Review began 07/14/2021 Review ended 08/26/2021 Published 09/10/2021

๑) Copyright 2021

Asly et al. This is an open access article distributed under the terms of the Creative Commons Attribution License CC-BY 4.0 which permits unrestricted use, distribution, and reproduction in any medium, provided the original author and source are credited.

\section{Osteoarticular Manifestations of Prolidase Deficiency and Disability: Case Reports of Two Moroccan Sisters}

\author{
Mouna Asly ${ }^{1}$, Madiha Eljazouly ${ }^{2}$ \\ 1. Physical Medicine and Rehabilitation, Cheikh Khalifa International University Hospital, Mohamed VI University of \\ Health Sciences (UM6SS), Casablanca, MAR 2. Dermatology Unit, Cheikh Khalifa International University Hospital, \\ Mohammed VI University of Health Sciences (UM6SS), Casablanca, MAR
}

Corresponding author: Mouna Asly, mounaasly@gmail.com

Categories: Dermatology, Genetics, Physical Medicine \& Rehabilitation

Keywords: prolidase deficiency, osteoarticular manifestations, skin ulcers, skeletal deformities, musculoskeletal disability

\title{
Introduction
}

Prolidase Deficiency (PD) is a rare autosomal recessive disease associated with elevated plasma and urine imidodipeptides caused by mutations in the paroxysmal extreme pain disorder (PEPD) gene encoding for prolidase, an enzyme involved in the biosynthesis and degradation of collagen I, which is an important component of the organic extracellular matrix. The role of this matrix is to strengthen and support connective tissues, such as skin, bone, cartilage, tendons, and ligaments [1].

PD is defined by a protean clinical spectrum, characterized by lower limb ulcers, facial dysmorphisms, deafness, splenomegaly, cognitive impairment, and recurrent infections [2]. Bone and joint abnormalities were referred occasionally. This is a case study of two PD Moroccan sisters with skeletal deformities, causing significant disability. The consent was obtained from the patients for publication of the case and images.

\section{Case Presentation}

\section{Case report one}

Patient one, aged 39 years old, was admitted for lower limb deformities and gait disturbances. Since the age of five, the patient was kept under examination in the dermatology department for chronic ulcerations of the lower limbs, related to prolidase deficiency (PD). Anamnesis revealed first-degree parent consanguinity and a younger sister affected by the same disease.

Clinical examination found multiple geographic ulcers with elevated borders on the feet, ankles, and distal tibial areas on both legs, bilateral genu valgum, and bilateral irreducible equinus. The plantigrade posture of the feet, being impossible, the patient was walking on tiptoe with a significant risk of falls (Figures $1 \mathrm{~A}, 1 \mathrm{~B}$ ). Spine and upper limbs examination were normal. Knees and ankles x-rays showed significant demineralization and equinus, without joint involvement (Figure 1C). Orthopedic shoes, compensating the equinus and crutches have been proposed to improve balance and prevent falls. 


\section{Cureus}
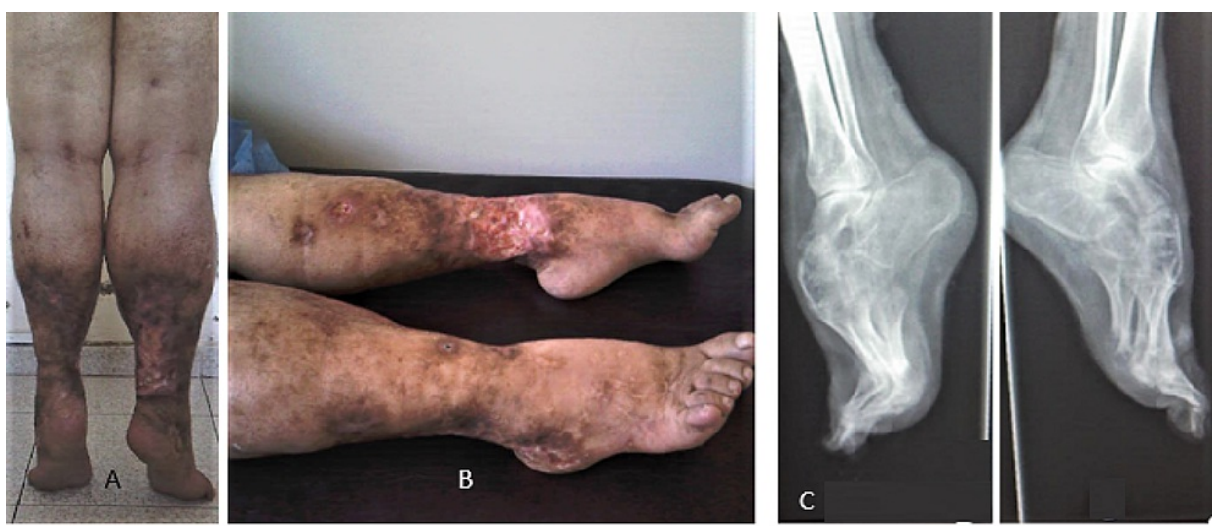

FIGURE 1: A-B: multiple geographic ulcers on the feet, ankles, and distal tibial areas on both legs, bilateral genu valgum, and bilateral irreducible equinus. C: Lateral foot $\mathrm{x}$-ray: demineralization, and equinus, without joint involvement.

\section{Case report two}

Patient two, aged 35 years old, is the younger sister of patient one and was also, diagnosed with PD when she was three years old.

Clinical examination found on the lower limbs, several ulcers, dry necrotic lesions, and retractile atrophic scars, bilateral genu valgum, irreducible equinus associated to varus of the right foot and valgus of the left one (Figure $2 A$ ), and fixed toes deformities: supra-adductus of fourth toes and of the right second toe (Figures $2 B, 2 C$ ). The patient is walking in a wheelchair. Spine and upper limbs examination were normal. Knees and ankles radiography $\mathrm{x}$-rays showed diffuse demineralization, bilateral genu valgum, fusion, and dislocation of the tarsal bones (Figure $2 D$ ).
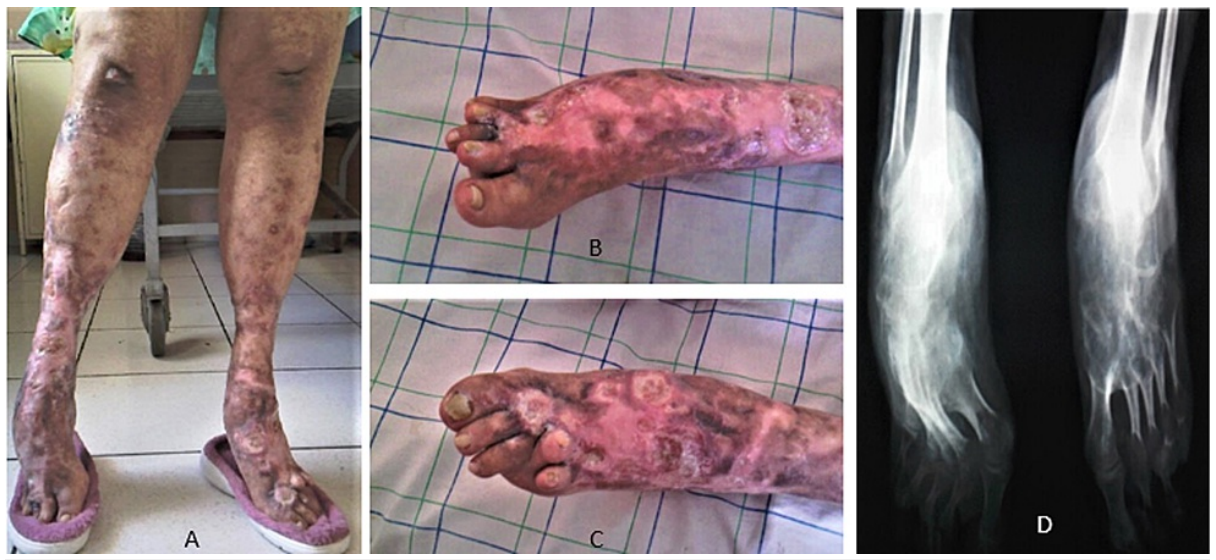

FIGURE 2: A: several ulcers, dry necrotic lesions, and retractile atrophic scars, bilateral genu valgum, irreducible equinus associated to varus of the right foot, and valgus of the left one. B-C: supra-adductus of fourth toes and of the right second toe. D: demineralization, bilateral genu valgum, fusion, and dislocation of the tarsal bones.

\section{Discussion}

PD is a rare autosomal recessive disorder. Since the first description of PD by Goodman in 1968, about 90 cases have been diagnosed all over the world. The incidence of PD is one to two per one million births, and it is more frequent in some populations, like the Druze and Arab Muslim minority in Israel [1]. 
imidodipeptides $\mathrm{x}$-proline and $\mathrm{x}$-hydroxyproline, which are excreted in the urine. Thus, the hallmark of PD is a massive imidopeptiduria associated with elevated proline or hydroxyproline containing dipeptides in plasma. Although there is considerable knowledge concerning the putative roles of the prolidase enzyme, the pathophysiology of PD is still not clearly understood, as there are marked phenotypic variability among affected individuals [1].

PD is a multisystem disorder, characterized by lower limb ulcers, facial dysmorphisms, deafness, splenomegaly, cognitive impairment, recurrent infections, and autoimmune manifestations $[1,2]$. Dermatological symptoms of PD are observed in the majority of patients, mainly in the form of leg ulcers which it is typically recurrent, severe, recalcitrant, and painful and usually appears in early childhood or in the teens. Telangiectasias, purpura, premature greying of the hair, photosensitivity, erythematous maculopapular rash, hypertrichosis, and dysmorphic facial features have also been described $[3,4]$.

Bone and joint abnormalities were referred occasionally. The common manifestations reported are joint laxity, talipes equinovarus, genu valgum, short stature, osteoporosis, arachnodactyly, hip dislocation, and delayed bone age. An association between systemic lupus erythematosus and prolidase deficiency has been described: patients who were already known to have prolidase deficiency developed clinical and immunological abnormalities consistent with a diagnosis of systemic lupus erythematosus (SLE) and following treatment with oral prednisolone their clinical condition has improved [5-8].

Other deformities involving the spine include spina bifida of $\mathrm{C} 3$ and 13th thoracic vertebrae, a fusion of $\mathrm{C} 2$ and C3, short neck, and kyphoscoliosis [9,10]. Muscular abnormalities were also found such as wasting of the small muscles of the hand with simian creases and digital clubbing, in the presence and in the absence of pulmonary abnormalities [6,11-12]. The diagnosis of prolidase deficiency is established by detection of either biallelic PEPD pathogenic variants or reduced prolidase enzyme activity in a patient who has characteristic clinical findings and imidodipeptiduria [13].

There is no curative treatment available for PD. It requires a multisystemic therapeutic approach to each symptom. Supportive treatment of skin and immunologic manifestations has been efficacious in some patients. Rehabilitative interventions are proposed as needed to address motor and cognitive impairments $[1,13]$. Genetic counseling is recommended if the PEPD pathogenic variants have been identified in the family. It allows carrier testing for at-risk relatives and prenatal testing for pregnancies at increased risk [13].

\section{Conclusions}

This paper reports osteoarticular deformities, related to PD, not described before such as deformities of the toes and the equinovalgus with fusion and dislocation of the tarsal bone. The severity of motor disability induced by deformities confirms the importance of a multidisciplinary approach, when treating patients with rare syndromes such as PD, to improve their quality of life.

\section{Additional Information}

\section{Disclosures}

Human subjects: Consent was obtained or waived by all participants in this study. Conflicts of interest: In compliance with the ICMJE uniform disclosure form, all authors declare the following: Payment/services info: All authors have declared that no financial support was received from any organization for the submitted work. Financial relationships: All authors have declared that they have no financial relationships at present or within the previous three years with any organizations that might have an interest in the submitted work. Other relationships: All authors have declared that there are no other relationships or activities that could appear to have influenced the submitted work.

\section{References}

1. Spodenkiewicz M, Spodenkiewicz M, Cleary M, et al.: Clinical genetics of prolidase deficiency: an updated review. Biology (Basel). 2020, 9:10.3390/biology9050108

2. Falik-Zaccai TC, Khayat M, Luder A, et al.: A broad spectrum of developmental delay in a large cohort of prolidase deficiency patients demonstrates marked interfamilial and intrafamilial phenotypic variability. Am J Med Genet B Neuropsychiatr Genet. 2010, 153B:46-56. 10.1002/ajmg.b.30945

3. Arata J, Umemura S, Yamamoto Y, Hagiyama M, Nohara N: Prolidase deficiency: its dermatological manifestations and some additional biochemical studies. Arch Dermatol. 1979, 115:62-67. 10.1001/archderm.1979.04010010034010

4. Ogata A, Tanaka S, Tomoda T, Murayama E, Endo F, Kikuchi I: Autosomal recessive prolidase deficiency. Three patients with recalcitrant ulcers. Arch Dermatol. 1981, 117:689-697. 10.1001/archderm.1981.01650110011009

5. Pasquali Ronchetti I, Quaglino D Jr, Dyne KM, Zanaboni G, Cetta G: Ultrastructural studies on dermis from prolidase deficient subjects. J Submicrosc Cytol Pathol. 1991, 23:439-45.

6. Shrinath M, Walter JH, Haeney M, Couriel JM, Lewis MA, Herrick AL: Prolidase deficiency and systemic lupus erythematosus. Arch Dis Child. 1997, 76:441-4. 10.1136/adc.76.5.441

7. Besio R, Maruelli S, Gioia R, et al.: Lack of prolidase causes a bone phenotype both in human and in mouse . Bone. 2015, 72:53-64. 10.1016/j.bone.2014.11.009 


\section{Cureus}

8. Marotte H, Gineyts E, Miossec P: Prolidase deficiency: a rare aetiology of arthritis . Joint Bone Spine. 2010, 77:88-9. 10.1016/j.jbspin.2009.07.004

9. Freij BJ, Levy HL, Dudin G, Mutasim D, Deeb M, Der Kaloustian VM: Clinical and biochemical characteristics of prolidase deficiency in siblings. Am J Med Genet. 1984, 19:561-71. 10.1002/ajmg.1320190319

10. Lacarbonara M, Cazzolla AP, Lacarbonara VA, Di Venere D, Capogreco M, Marzo G: Prolidase deficiency: dento-facial aspects in a paediatric patient. Eur J Paediatr Dent. 2014, 15:224-8.

11. Luder AS, Mandel H, Khayat M, Gurevich I, Frankel P, Rivlin J, Falik-Zaccai TC: Chronic lung disease and cystic fibrosis phenotype in prolidase deficiency: a newly recognized association. J Pediatr. 2007, 150:656-8. 10.1016/j.jpeds.2007.03.025

12. Kelly JJ, Freeman AF, Wang H, Cowen EW, Kong HH: An Amish boy with recurrent ulcerations of the lower extremities, telangiectases of the hands, and chronic lung disease. J Am Acad Dermatol. 2010, 62:1031-4. 10.1016/j.jaad.2009.12.038

13. Ferreira C, Wang H: Prolidase deficiency. GeneReviews ${ }^{\circledR}$ [Internet]. Adam MP, Ardinger HH, Pagon RA, Wallace SE, Bean LJH, Mirzaa G, Amemiya A, (ed): University of Washington, Seattle, Seattle (WA); 2015. https://pubmed.ncbi.nlm.nih.gov/26110198/ 